\title{
Communication \\ A Proposal for a Standardized Approach to Inducing Low Energy Availability in Athletes
}

\author{
Iva Jurov ${ }^{1, *\left(\mathbb{D}, \text { Nicola Keay }^{2} \text {, Vedran Hadžić }\right.}{ }^{1}$ (D) and Samo Rauter ${ }^{1}$ \\ 1 Faculty of Sport, University of Ljubljana, Gortanova 22, 1000 Ljubljana, Slovenia; \\ Vedran.Hadzic@fsp.uni-lj.si (V.H.); Samo.Rauter@fsp.uni-lj.si (S.R.) \\ 2 Department of Sport and Exercise Sciences, Durham University, Durham DH1 3LY, UK; \\ nickykeayfrancis@googlemail.com \\ * Correspondence: iva.jurov@gmail.com
}

Citation: Jurov, I.; Keay, N.; Hadžić,

V.; Rauter, S. A Proposal for a

Standardized Approach to Inducing

Low Energy Availability in Athletes.

Appl. Sci. 2021, 11, 6679. https://

doi.org/10.3390/app11156679

Academic Editors: Christian

W. Dawson, Alessandro de Sire,

Jörg Spörri and Matej Supej

Received: 27 May 2021

Accepted: 19 July 2021

Published: 21 July 2021

Publisher's Note: MDPI stays neutral with regard to jurisdictional claims in published maps and institutional affiliations.

Copyright: (C) 2021 by the authors. Licensee MDPI, Basel, Switzerland. This article is an open access article distributed under the terms and conditions of the Creative Commons Attribution (CC BY) license (https:/ / creativecommons.org/licenses/by/ $4.0 /)$.
Featured Application: Using a standardized approach to inducing low energy availability in athletes could enable determination of the threshold for low energy availability in men resulting in better performance and health.

Abstract: Low energy availability in athletes is an insufficiently researched phenomenon due to lack of a universal methodology. Current objective and subjective methods for assessing low energy availability lack in accuracy, are not used with a standardized approach and fail to provide comparable, consistent results. Research in male athletes is even more challenging than in females. It is still not known what the threshold for low energy availability is when negative effects on health and performance occur. This is why in this paper a two-way standardized, systematic and controlled protocol for inducing low energy availability in free-living athletes is proposed. Ways of inducing low energy availability in athletes are described with a systematic approach to ensure accurate results. We suggest this is how new tools for assessing low energy availability can be developed with less burden on the athlete and the scientist. Analysis of each proposed protocol provides a rationale for their use. Future research directions are suggested for determining the threshold for low energy availability and determining the critical duration for its negative effects. Finally, we suggest a practical outcome of using the proposed research approach for health practitioners and coaches in order to protect athlete's well-being.

Keywords: low energy availability; relative energy deficiency in sport; energy availability; energy balance; energy expenditure

\section{Introduction}

Low energy availability (LEA) means that at the end of the day insufficient energy was left to the body to support processes needed for healthy living [1]. In athletes, LEA affects health and performance. It can result in Relative Energy Deficiency in Sport (RED-S) syndrome [1,2]. RED-S is a syndrome that causes hormonal imbalance and metabolic dysfunction [1]. It can occur in athletes trying to regulate body mass or aesthetic as a result of an intentional inappropriate nutritional restriction coupled with high exercise energy expenditure, or unintentionally due to high training loads [2]. It clinically presents itself as issues concerning menstrual function (in female athletes), bone health, immune system, gastrointestinal function and cardiovascular system [1]. It also negatively affects well-being and performance, but all effects are still now known [3]. Energy Availability (EA) has proven to be more useful in athletes than Energy Balance (EB) for assessing health [4]. However, LEA can easily remain unrecognised as there is no clear clinical sign posting towards it. In females, less than $45 \mathrm{kcal}$ available per kg of Fat Free Mass (FFM) per day results in disruption of hormone networks and bone turn over [5]. For males, this threshold is hypothesized to be lower. For males, the lower two thresholds for LEA 
have been proposed; $15 \mathrm{kcal} / \mathrm{kg}$ FFM/day [6] and $30 \mathrm{kcal} / \mathrm{kg}$ FFM/day [7]. Inability to determine a threshold for LEA in men remains for several reasons. One of these is that men do not exhibit clear clinical signs of LEA such as amenorrhea in females [8]. However, more importantly, the methodology for determining EA in either men or women is not universal [9]. Subjective assessment with questionnaires and estimations has proven to be useful $[10,11]$ but it does not solve the problem of determining the threshold. Neither has it provided any conclusions on which subjective method is the most suitable [9]. Furthermore, different approaches to measuring EA with objective methods (like using acceleromenters or heart rate monitors for measuring energy expenditure [12]) add to the problem of comparability of results [9]. This does not help in finding better screening and assessment tools or markers that would provide a reasonably low-cost and low-burden methods for determining LEA. The fact that still no threshold for EA has been determined in men, causes further issues in research in assessing LEA causes/consequences [9].

In addition to the methodological problems, the duration and possible other factors that propagate LEA are still not known. A systematical approach to inducing LEA in previously healthy athletes is needed to determine a threshold for LEA or to dismiss this hypothesis and determine a range when LEA can occur. This LEA-induced state could more accurately provide conclusions on how long this needs to persist to negatively impact health/performance. A controlled state of induced LEA would also eliminate all possible inaccuracies that occur in assessing EA in free-living athletes. Performing LEA in controlled, "laboratory-like" environment, yet in real athletes, would also give relevant information on which markers could be used in future for easier assessment without the long-lasting, high-burden and error-prone objective methodology.

This is why we propose a two-way standardized, systematic and controlled protocol for inducing LEA in free-living athletes. This protocol should be researched together with plausible health and performance outcomes with objective and subjective methods.

\section{Materials and Methods}

Objective methodology for measuring EA should consist of as accurate measurement of all three components as possible: Energy Intake (EI), Exercise Energy Expenditure (EEE) and FFM. When EA is calculated, this baseline value can be used for further calculations in the induced LEA protocol.

\subsection{Methods for Measuring EA}

EI is probably the most error-prone variable of the equation. Currently, there is no gold standard for measuring EI but diary logs are most commonly used [13]. A diary log or food record is where all food and drinks that are consumed are recorded by the participant for a specified number of days [13]. It seems that additional measures as taking photographic evidence with all food ingested, detailed instructions with education on food measurements and regular contact with participants can be very helpful [13]. In this paper, dietary assessment will not be discussed in detail.

\subsection{Methods for Measuring EEE}

A great comparison for energy expenditure measurements and assessment has been made by Strath et al. [12]. Striving for accuracy measuring EEE with heart rate (HR) monitors during moderate and vigorous intensities is the best option. Unfortunately, HR is affected by other factors in lower intensities, such as caffeine ingestion or psychological stimuli. In these cases, accelerometer might be appropriate but only in activities that do not include cycling, stair use or resistance training. Another disadvantage in measuring EEE from HR is that in state or overreaching HR maximal values cannot be reached [14]. Submaximal HR values in induced LEA state could underestimate EEE. In this way, when fatigue progresses it is also progressively hard to achieve the predetermined EEE values. 


\subsection{Methods for Measuring FFM}

FFM measurement can be done in more ways, but two of them are widely used in research setting due to accuracy or low burden and cost. Still considered the golden standard, dual energy X-ray absorptiometry, can estimate FFM with low precision errors [15]. It is not as accessible, relatively more expensive and provides small doses of radiation. The bioelectrical impedance is another way of precise FFM measurement [16]. Subjects must be instructed to be hydrated properly before measurement and must avoid physical activities several hours before. It is cheaper and is more accessible. The most important thing when observing EA is to use the same methodology when comparing inter-individual or intra-individual results, otherwise changes in FFM can be observed due to flawed methodology.

\section{Results}

3.1. A Two-Way Approach to Inducing LEA

EA is calculated as

$$
\mathrm{EA}=(\mathrm{EI}-\mathrm{EEE}) / \mathrm{FFM} .
$$

Lowering EA from a mathematical standpoint is straightforward. There are three ways EA can be lowered: Bz desreasing EI or by increasing EEE and/or FFM. The body composition is relatively stable and it is unreasonable to expect a drastic change in FFM in experimental setting in previously healthy individuals. Changing EI and EEE is, however, relatively simple and done every day in athlete's periodization process during the season.

\subsection{High-EEE Protocol}

The first protocol, the high-EEE protocol, is set in a way of increasing EEE without any changes in EI and FFM (Figure 1). A subject is measured during the baseline period of 7 days to determine real-life EEE, EI and current FFM as described in the methods for measuring EA [17]. Subject's baseline EA value is calculated. Then, an increased EEE is calculated based on a new, lower EA value:

$$
\mathrm{EEE}=\mathrm{EI}-\mathrm{EA} * \mathrm{FFM}
$$

\section{adequate EA}

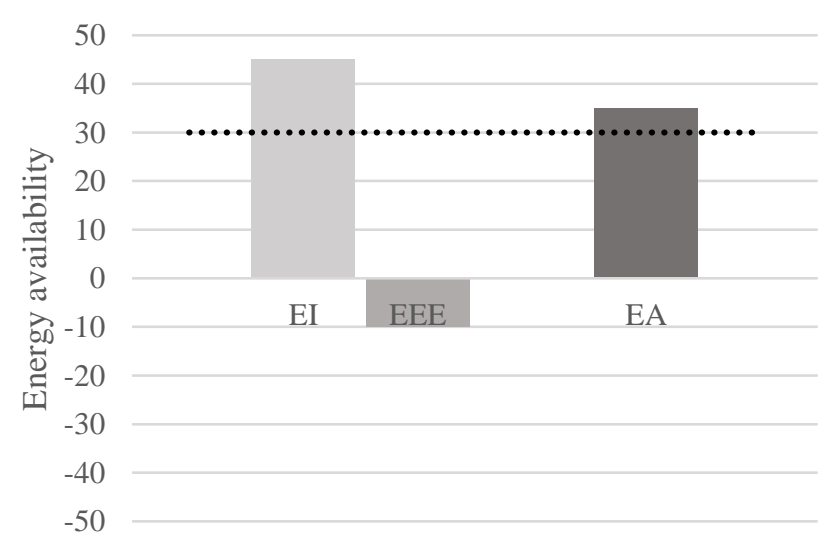

\section{high-EEE protocol}

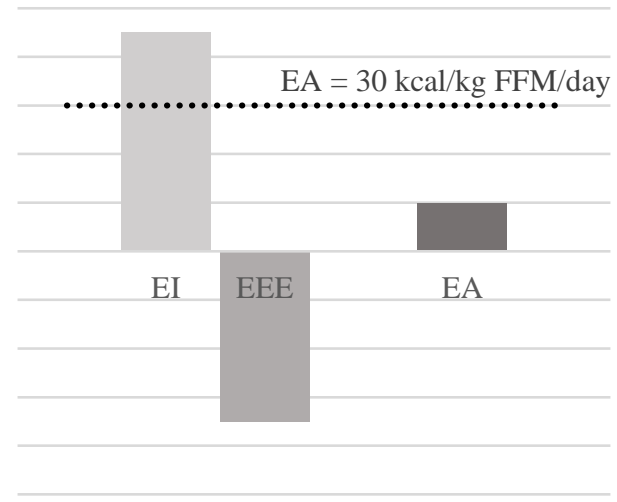

Figure 1. A schematic representation of high-EEE protocol. EI remains identical, while EEE is increased in a way to reach a favorable EA.

When a daily EEE value has been calculated, this must be transformed into actual training plan comprised of duration and intensity. As we know, different training intensities influence metabolism differently; we propose baseline training characteristics to be repeated in longer duration in more training units. This means a subject would have more identical training units from baseline that would be scattered across a day. Some studies increased EEE by simply setting a calculated duration of an activity at $70 \%$ of maximal 
oxygen consumption to achieve the desired EA $[5,18,19]$. This is appropriate for sedentary, normally active population. However, for athletes such an approach might not represent an ideal scenario of increased training volume. In reality, increases in training load are very rarely done in this way. Their training units are more frequently increased in volume and intensity based on their training characteristic and not merely at $70 \%$ maximal oxygen consumption. We suggest using actual athlete's training characteristics from baseline measurements and repeating them in more training units across the week might more accurately represent reality.

Identical EI can be achieved when baseline EI is simply repeated in the same way. Participant must strictly follow their well-recorded diary log for the same time period or for multiplied time period in case of longer LEA duration. For the participant, following their eating protocol represents smaller burden than following a new diet regime. However, as time passes in the protocol, appetite reduction/increase becomes progressively hard to withstand. It is crucial that an athlete strictly follows their eating plan. In this way, the risk of different macronutrient ratio and different energy value is eliminated.

To ensure the constant value of FFM we propose inducing LEA shortly after measuring baseline values. We know that body composition does not change in matter of days but in longer time periods. If the protocol would induce LEA in more than 2 weeks, we propose FFM would be measured in every 7 days after 2 weeks of measurements. In this way, correction of EEE change would be made to fit the EA goals accordingly.

Other internal and external factors influencing high-EEE protocol are represented in Table 1.

Table 1. SWOT analysis of the high-EEE protocol (SWOT $=$ Strength, Weakness, Opportunity and Threat Analysis, EEE = exercise energy expenditure, EI = energy intake, LEA = low energy availability, $\mathrm{EB}=$ energy balance).

\begin{tabular}{|c|c|}
\hline Strenghts & Opportunities \\
\hline $\begin{array}{l}\text { - } \quad \text { easy to measure. } \\
\text { - } \quad \text { meass error-prone } \\
\text { accuracy of the athlete } \\
\text { - less burdening on some athletes who } \\
\text { prefer EI to remain the same }\end{array}$ & $\begin{array}{l}\text { to compare differences when EEE is increased } \\
\text { with low/medium/high intensity or with the } \\
\text { same intensities and modalities as in a } \\
\text { real setting } \\
\text { to set individual's maximum training volume } \\
\text { before LEA occurs }\end{array}$ \\
\hline Weaknesses & Threats \\
\hline $\begin{array}{l}\text { - } \\
\text { monifficulties in settings where HR } \\
\text { in water) } \\
\text { reaching extremely low values of LEA in } \\
\text { endurance disciplines could be hard to } \\
\text { achieve where baseline training volumes } \\
\text { are already very high (too many hours } \\
\text { spent in training would reduce/eliminate } \\
\text { recovery and sleep time and time } \\
\text { for eating) }\end{array}$ & $\begin{array}{l}\text { HR lowers in cases of increasing training } \\
\text { volume, this makes reaching EEE increasingly } \\
\text { difficult. The question remains if EEE is still } \\
\text { correlated in the same way to HR as in } \\
\text { rested state } \\
\text { by changing EEE, the excess post-exercise } \\
\text { oxygen consumption is also changed which } \\
\text { causes EB to be different than if LEA is induced } \\
\text { by EI decrease. Impact of EB could have an } \\
\text { effect on LEA consequences. }\end{array}$ \\
\hline
\end{tabular}

\subsection{Low-EI Protocol}

The second protocol requires only EI to be lowered (Figure 2). Macronutrient content probably influences LEA in more ways [7]. To eliminate the impact from nutritional standpoint we suggest equal reductions is protein, fat and carbohydrate energy daily content. This means EI should be changed by equally reducing all portion sizes by equally reducing macronutrients' energy value. 


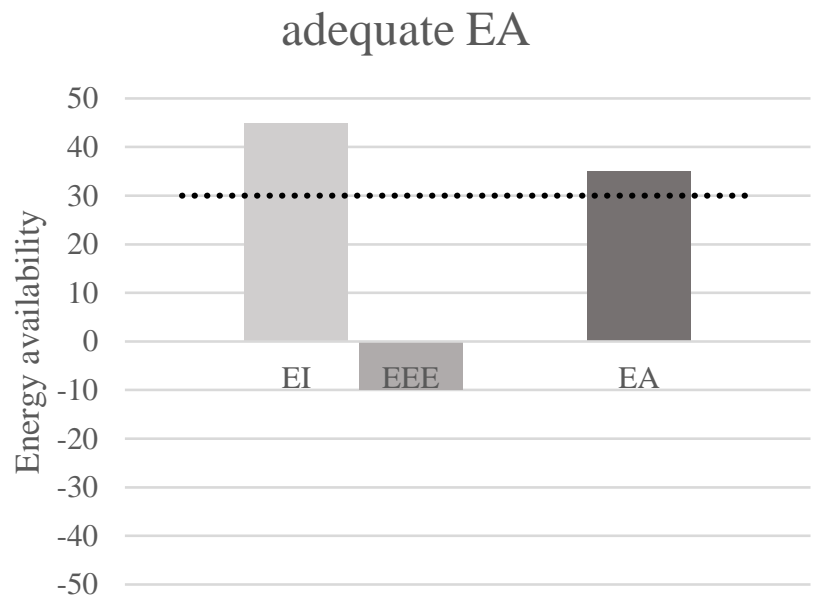

\section{low-EI protocol}

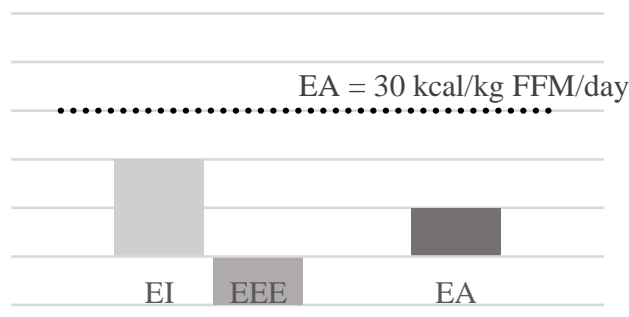

Figure 2. A schematic representation of low-EI protocol. EEE remains identical, while EI is reduced in a way to reach a target EA.

Unchanged EEE is achievable by repeating identical training regime than in the baseline measurements.

As in the high-EEE protocol, the same starting FFM should be ensured and in case of a longer protocol multiple corrections be made according to FFM changes to ensure the calculated EA value. As concluded by Melby et al. [20] there seem to be powerful biological processes and environmental factors opposing food restriction in individuals trying to reduce body mass. This means that as the individuals reduce EI without any increases in physical activity, they require extraordinary willpower to fight these pressures that do not seem to dissipate over time [20]. We speculate that this protocol might be more burdening on the athlete from motivational standpoint. Other characteristics of low-EI protocol are represented in Table 2.

Table 2. SWOT analysis of low-EI protocol (EEE = exercise energy expenditure, EI = energy intake, LEA = low energy availability, EB = energy balance).

\begin{tabular}{|c|c|}
\hline Strenghts & Opportunities \\
\hline $\begin{array}{l}\text { - training volume remains the same, which } \\
\text { is easier to achieve from duration } \\
\text { standpoint } \\
\text { lowering EI with unchanged EEE might } \\
\text { be easier for some subjects }\end{array}$ & $\begin{array}{l}\text { to compare differences when EI is reduced } \\
\text { with equal meal distribution across the day or } \\
\text { if EI is reduced by eliminating some meals (but } \\
\text { retaining the daily macronutrient content) }\end{array}$ \\
\hline Weaknesses & Threats \\
\hline $\begin{array}{l}\text { - } \quad \text { new EI must be calculated by an } \\
\text { experienced dietitian } \\
\text { subjects must be monitored while eating } \\
\text { or instructed very clearly on their new } \\
\text { eating regime with smaller portion sizes, } \\
\text { that are distributed identically across the } \\
\text { day as in the baseline measurements }\end{array}$ & $\begin{array}{l}\text { electrolyte disturbances must be prevented by } \\
\text { enabling free salt consumption } \\
\text { micronutrients should be supplemented to } \\
\text { avoid any deficiencies } \\
\text { in severe cases of LEA, ketosis might occur that } \\
\text { can be tolerated differently by subjects } \\
\text { depending on their previous eating habits } \\
\text { by changing EI, the diet induced } \\
\text { thermogenesis is reduced, so EB is not the same } \\
\text { as in case of induced LEA with increased EEE }\end{array}$ \\
\hline
\end{tabular}

\section{Discussion}

\subsection{Measuring EA}

The 3-5-day diary records are considered to be more appropriate than logs of longer duration due to less burden on the participant, especially in the non-athletic population. However, for EA assessment longer periods might have a greater value since there are daily 
fluctuations in EB and EA. Short duration excursions into EA might provide a distorted image of an athlete's status. A review in dietary assessment techniques concluded monitoring EI should be performed the whole time while measuring energy expenditure [13]. This is why it seems that the whole micro cycle in training periodization, i.e., the whole week (7 days), should be included in measurements when assessing EA [13]. This has been done in some papers that included measuring EA with dietary logs [10,17,21-23], but also shorter durations of 5 days [24,25], 4 days [26] and 3 days $[7,27,28]$ have been used. This could be one of the reasons for inconsistent results. In our research group, we have demonstrated that a 7-day EI measuring period together with detailed EEE measurement shows lower EA values in male athletes as expected since average EA was below $30 \mathrm{kcal} / \mathrm{kg}$ FFM/day. We included rest days and training days, which we think is necessary when observing EA. The disadvantage of a 7-day diary log is more burden on the dietitian [29], but even small errors in EA can greatly influence EA calculation. This is why we propose a 7-day period should be used for EI assessment as part of EA measurement.

As in the case of EI measurement, a whole micro-cycle consisting of 7 consecutive days should be included in the analysis. This would include possible rest days and days of higher training volume or different intensities. At this time, we do not know how long LEA has to last to cause undesirable effects. We know that within-day energy deficiency is associated with these effects $[21,30]$. Nevertheless, health related consequences such as poor bone health, reproductive status, or compromised immunity do not happen over few days but more probably over longer periods of time. This is why observing EA over more than just a few days could be more appropriate. We suggest variability in EEE over 7 days in training week should be included in EA assessment. This would provide a better representation of EA status in an athlete than just 3 or 5 days.

\subsection{How Much (or Little) Is Enough?}

There is still an unanswered question about the threshold value for LEA in men and whether there is a threshold at all. The reason for inconsistency in finding a threshold in men could be due to different approaches to measuring LEA. We propose a two-way model to approach this issue in a systematical way. The first approach is to lower EA in previously healthy individuals to a set value of 30,25, 20, 15, 10 or even 5 (Figure 3). Pioneer work in females has been done in similar manner [5], but the lowest EA in that research was 10. Since males appear to have a greater tolerance for reduced EA, a value of 5 might be necessary to detect any changes in health or performance markers. Another factor is that in research by Loucks an Thuma [5], participants were sedentary women. In athletes (especially male), longer and more severe restrictions in EA might be necessary.

There is another notion that there might not be any cutoff value for LEA at all [1]. If there truly is a spectrum (but not a single threshold) where LEA in men can occur, this could be explained with reduction in EA that is more personalized to the athlete. This is why the second approach is to set a proportional reduction in EA-a reduction of $75 \%, 50 \%$, $25 \%$ or even $10 \%$ from the baseline EA value (Figure 3 ). This would produce various values of EA, but reduction would be more individualized to the athlete. This could produce not a single value of LEA but a range of values where progression of lowering EA would elicit severity of undesired effects. 

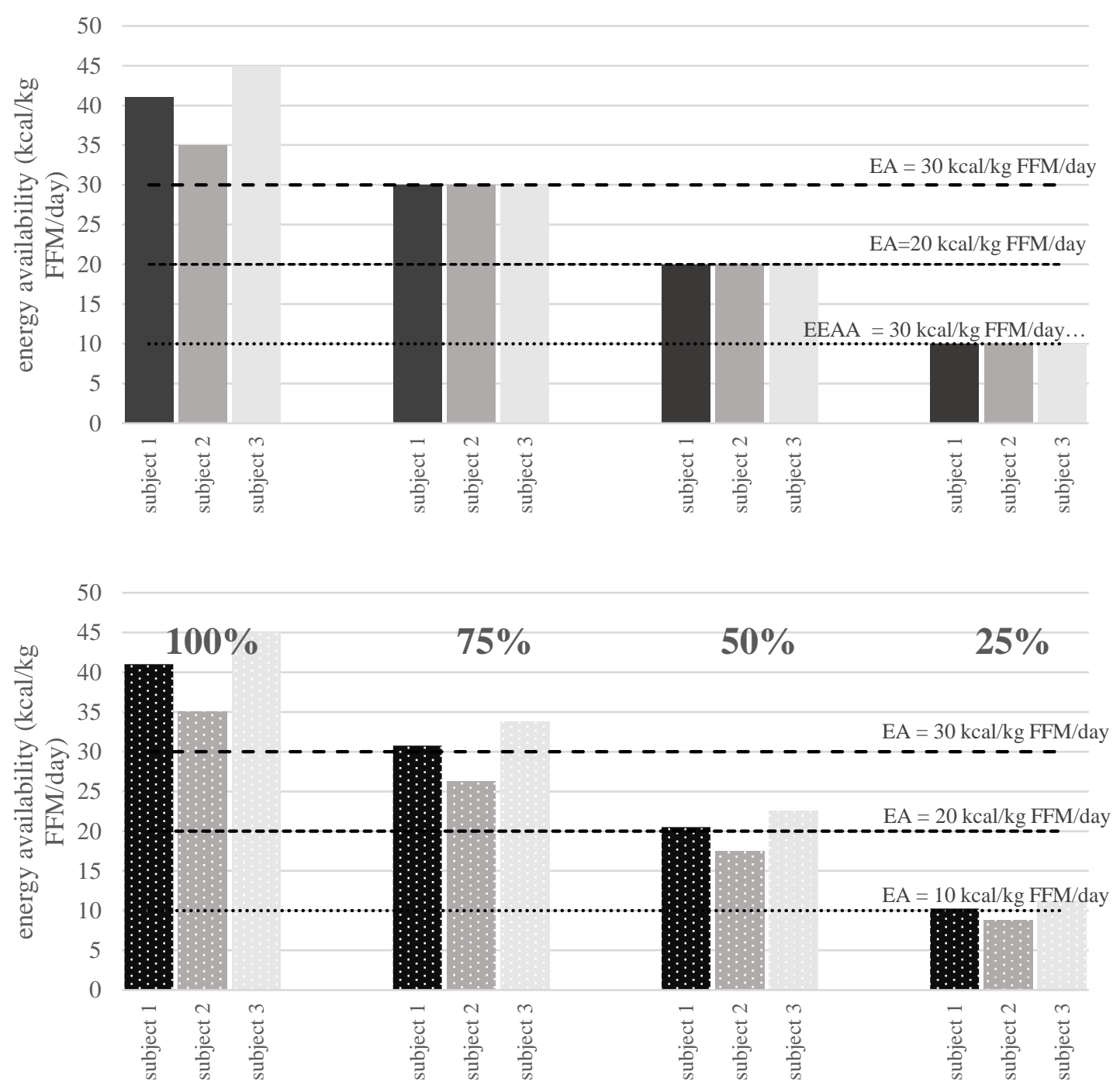

Figure 3. The difference in lowering EA to an absolute threshold value (30, 20 and $10 \mathrm{kcal} / \mathrm{kg}$ FFM/day) or relative to baseline values $(75 \%, 50 \%$ and $25 \%$ ) in a more individualized manner on 3 representative subjects.

\subsection{How Long Is Enough to Induce LEA Clinical Effects?}

Excellent work that has been done so far gives us an insight into duration of LEA. In females, Loucks and Heath [19] showed a low-T3 syndrome in exercising women due to $\mathrm{EA}=30 \mathrm{kcal} / \mathrm{kg}$ FFM/day in only four days. A second important work was conducted on sedentary women that showed a disruption in pulsatility of luteinizing hormone under the threshold of $30 \mathrm{kcal} / \mathrm{kg}$ FFM/day in only five days [5]. Induced LEA in 3 days in active women resulted in a significant decrease in bone formation [18].

Previous research by Papageorgiou compared effects of LEA on bone formation with a similar approach as the high-EEE and low-EI protocol [18]. The protocol used in that research lasted only three days and found no differences in hormone concentrations (IGF-1, T3, insulin, leptin and 17 $\beta$-estradiol). However, bone formation was reduced in the dietary energy restriction group. The subjects included were eumenorrheic women. As often recognized, men might not experience the same consequences of suboptimal EA as women. In addition, there is an important difference between sedentary/moderately active subjects and athletes. Longer intervention studies on athletes might provide more relevant data on reduced EA duration that produces health/performance detriments. Four weeks of reduced EA in elite male rowers induced decreased Resting Energy Expenditure (REE). The study design comprised of intensified training that was not matched by an optimal EI [31]. A similar design on cyclist elicited a decrease in REE in 3-week intensified 
training load [32] followed by a two week recovery period. There was no significant difference in T3 and leptin. Importantly, they already detected aerobic and anaerobic performance decline.

This suggests reduced EA in men could have negative effects in three weeks or less. We speculate athletes do not exhibit critical changes in health and performance in 3 or 5 days as shown in sedentary/active females. We hypothesize athletes possess a greater ability of sustaining physical stress and energy deficiency. To show any meaningful changes of LEA in athletes, we suggest protocol should last at least 2 weeks. This is also a duration of typical intensified period in athlete's periodization process. Anything less can cause acute changes that might not affect athlete in long-term.

To summarize, there is currently no answer on critical duration of LEA. We might discover more by firstly determining the threshold. Then, we suggest protocols should be designed to explore what is the shortest duration of LEA that athletes can withstand without important changes in their performance and health. This is not only important for health-safety of the athletes in real life but also for the participants in future studies. Based on our current knowledge, starting protocols at 14 days might be the most appropriate strategy.

\subsection{What Next?}

There are clearly a lot of unanswered questions. When science provides relevant conclusions for LEA severity and duration, we might be able to offer better assessment and screening tools for LEA. This would enable easy monitoring of all athletes at risk with a goal for their optimal results while remaining healthy. Heikura et al. [10] already suggested blood markers or questionnaires might be a better approach to determining LEA due to inaccuracy and burden of the objective LEA measurement. In addition, REE and blood markers might be included in future in LEA management [1]. Testosterone [33] and IGF-1 [34] might prove to be of value, but this needs to be explored in controlled conditions. Before setting any final recommendations on these more convenient methods, we believe there is a need of more original work with objective methodology done with well-trained and elite athletes. Further research should be aimed at comparing differences in REE changes, hormonal markers and performance outcomes between the two protocols. More performance studies could enable us to better understand LEA management. Finally, knowledge from genetic markets and diet optimization (nutrigenomics) should be expanded in these protocols as they could play an important role in LEA.

\section{Conclusions}

Reduced EA has a great prevalence and causes multiple negative, sometimes devastating effects on athletes. A universal protocol inducing LEA would give us a better understanding of suboptimal EA in athletes. We propose a two-way approach for inducing LEA in a systematic way. This method would reduce the inconsistency in results due to current various approaches for measuring LEA in men and women. It would also provide information on potential LEA cut-off value in men and critical LEA duration. This knowledge might importantly influence the duration of rapid weight management practices and intensified-training camps in athletes with a goal to keep an athlete in their optimal well-being and physical form. Coaches and sports professionals need to know how to avoid LEA while still imposing high training loads on athletes in order to improve performance. Finally, understanding differences between the high-EEE and low-EI protocol could lead health practitioners to a better management of RED-S. Knowing potential different outcomes by the two protocols could influence their decision on managing EI, EEE or both in a RED-S affected athlete.

Author Contributions: Conceptualization, I.J.; methodology, I.J.; validation, I.J., N.K., S.R., V.H., data curation, I.J.; writing—original draft preparation, I.J.; writing—review and editing, I.J., N.K., S.R., V.H., supervision, N.K.; All authors have read and agreed to the published version of the manuscript. 
Funding: This research was funded by the Slovenian Research Agency (research grant number: P5-0147). The funder had no role in study design, data collection and analysis, decision to publish, or preparation of the manuscript.

Institutional Review Board Statement: Not applicable.

Informed Consent Statement: Not applicable.

Conflicts of Interest: The authors declare no conflict of interest.

\section{References}

1. Mountjoy, M.; Sundgot-Borgen, J.; Burke, L.; Ackerman, K.E.; Blauwet, C.; Constantini, N.; Lebrun, C.; Lundy, B.; Melin, A.; Meyer, N.; et al. International Olympic Committee (IOC) Consensus Statement on Relative Energy Deficiency in Sport (RED-S): 2018 Update. Int. J. Sport Nutr. Exerc. Metab. 2018, 28, 316-331. [CrossRef]

2. Mountjoy, M.; Sundgot-Borgen, J.; Burke, L.; Carter, S.; Constantini, N.; Lebrun, C.; Meyer, N.; Sherman, R.; Steffen, K.; Budgett, R.; et al. The IOC consensus statement: Beyond the Female Athlete Triad-Relative Energy Deficiency in Sport (RED-S). Br. J. Sports Med. 2014, 48, 491-497. [CrossRef]

3. Logue, D.; Madigan, S.M.; Delahunt, E.; Heinen, M.; Mc Donnell, S.J.; Corish, C.A. Low Energy Availability in Athletes: A Review of Prevalence, Dietary Patterns, Physiological Health, and Sports Performance. Sports Med. 2018, 48, 73-96. [CrossRef]

4. Loucks, A.B.; Kiens, B.; Wright, H.H. Energy availability in athletes. J. Sports Sci. 2011, 29, 37-41. [CrossRef] [PubMed]

5. Loucks, A.B.; Thuma, J.R. Luteinizing hormone pulsatility is disrupted at a threshold of energy availability in regularly menstruating women. J. Clin. Endocrinol. Metab. 2003, 88, 297-311. [CrossRef] [PubMed]

6. Koehler, K.; Hoerner, N.R.; Gibbs, J.C.; Zinner, C.; Braun, H.; De Souza, M.J.; Schaenzer, W. Low energy availability in exercising men is associated with reduced leptin and insulin but not with changes in other metabolic hormones. J. Sports Sci. 2016, 34, 1921-1929. [CrossRef]

7. Viner, R.T.; Harris, M.; Berning, J.R.; Meyer, N.L. Energy availability and dietary patterns of adult male and female competitive cyclists with lower than expected bone mineral density. Int. J. Sport Nutr. Exerc. Metab. 2015, 25, 594-602. [CrossRef] [PubMed]

8. Burke, L.M.; Close, G.L.; Lundy, B.; Mooses, M.; Morton, J.P.; Tenforde, A.S. Relative Energy Deficiency in Sport in Male Athletes: A Commentary on Its Presentation Among Selected Groups of Male Athletes. Int. J. Sport Nutr. Exerc. Metab. 2018, 28, 364-374. [CrossRef]

9. Burke, L.M.; Lundy, B.; Fahrenholtz, I.L.; Melin, A.K. Pitfalls of Conducting and Interpreting Estimates of Energy Availability in Free-Living Athletes. Int. J. Sport Nutr. Exerc. Metab. 2018, 28, 350-363. [CrossRef]

10. Heikura, I.A.; Stellingwerff, T.; Bergland, D.; Mero, A.A.; Burke, L.M. Low Energy Availability Is Difficult to Assess but Outcomes Have Large Impact on Bone Injury Rates in Elite Distance Athletes. Int. J. Sport Nutr. Exerc. Metab. 2018, 28, 403-411. [CrossRef]

11. Keay, N.; Francis, G.; Hind, K. Low energy availability assessed by a sport-specific questionnaire and clinical interview indicative of bone health, endocrine profile and cycling performance in competitive male cyclists. BMJ Open Sport Exerc. Med. 2018, 4, e000424. [CrossRef]

12. Strath, S.J.; Kaminsky, L.A.; Ainsworth, B.E.; Ekelund, U.; Freedson, P.S.; Gary, R.A.; Richardson, C.R.; Smith, D.T.; Swartz, A.M. Guide to the assessment of physical activity: Clinical and research applications: A scientific statement from the American Heart Association. Circulation 2013, 128, 2259-2279. [CrossRef]

13. Capling, L.; Beck, K.; Gifford, J.; Slater, G.; Flood, V.; O'Connor, H.; Capling, L.; Beck, K.L.; Gifford, J.A.; Slater, G.; et al. Validity of Dietary Assessment in Athletes: A Systematic Review. Nutrients 2017, 9, 1313. [CrossRef]

14. Halson, S.L.; Bridge, M.W.; Meeusen, R.; Busschaert, B.; Gleeson, M.; Jones, D.A.; Jeukendrup, A.E. Time course of performance changes and fatigue markers during intensified training in trained cyclists. J. Appl. Physiol. 2002, 93, 947-956. [CrossRef]

15. Buckinx, F.; Landi, F.; Cesari, M.; Fielding, R.A.; Visser, M.; Engelke, K.; Maggi, S.; Dennison, E.; Al-Daghri, N.M.; Allepaerts, S.; et al. Pitfalls in the measurement of muscle mass: A need for a reference standard. J. Cachexia. Sarcopenia Muscle 2018, 9, 269-278. [CrossRef]

16. Brodie, D.; Moscrip, V.; Hutcheon, R. Body composition measurement: A review of hydrodensitometry, anthropometry, and impedance methods. Nutrition 1998, 14, 296-310. [CrossRef]

17. Jurov, I.; Keay, N.; Hadzic, V. Relationship between energy availability, energy conservation and cognitive restraint with performance measures in male endurance athletes. J. Int. Soc. Sports Nutr. 2021, 18, 24. [CrossRef]

18. Papageorgiou, M.; Martin, D.; Colgan, H.; Cooper, S.; Greeves, J.P.; Tang, J.C.Y.; Fraser, W.D.; Elliott-Sale, K.J.; Sale, C. Bone metabolic responses to low energy availability achieved by diet or exercise in active eumenorrheic women. Bone 2018, 114, 181-188. [CrossRef]

19. Loucks, A.B.; Heath, E.M. Induction of low-T3 syndrome in exercising women occurs at a threshold of energy availability. Am. J. Physiol. Integr. Comp. Physiol. 1994, 266, 817-823. [CrossRef]

20. Melby, C.L.; Paris, H.L.; Drew Sayer, R.; Bell, C.; Hill, J.O. Increasing energy flux to maintain diet-induced weight loss. Nutrients 2019, 11, 2533. [CrossRef]

21. Torstveit, M.K.; Fahrenholtz, I.; Stenqvist, T.B.; Sylta, Ø.; Melin, A. Within-day Energy Deficiency and Metabolic Perturbation in Male Endurance Athletes. Int. J. Sport Nutr. Exerc. Metab. 2018, 28, 419-427. [CrossRef] 
22. Tornberg, Å.B.; Melin, A.; Koivula, F.M.; Johansson, A.; Skouby, S.; Faber, J.; Sjödin, A. Reduced Neuromuscular Performance in Amenorrheic Elite Endurance Athletes. Med. Sci. Sports Exerc. 2017, 49, 2478-2485. [CrossRef]

23. Braun, H.; von Andrian-Werburg, J.; Schänzer, W.; Thevis, M. Nutrition Status of Young Elite Female German Football Players. Pediatr. Exerc. Sci. 2018, 30, 157-167. [CrossRef] [PubMed]

24. Vescovi, J.D.; VanHeest, J.L. Case Study: Impact of Inter- and Intra-Day Energy Parameters on Bone Health, Menstrual Function, and Hormones in an Elite Junior Female Triathlete. Int. J. Sport Nutr. Exerc. Metab. 2016, 26, 363-369. [CrossRef]

25. Muia, E.N.; Wright, H.H.; Onywera, V.O.; Kuria, E.N. Adolescent elite Kenyan runners are at risk for energy deficiency, menstrual dysfunction and disordered eating. J. Sports Sci. 2016, 34, 598-606. [CrossRef]

26. Schaal, K.; Tiollier, E.; Le Meur, Y.; Casazza, G.; Hausswirth, C. Elite synchronized swimmers display decreased energy availability during intensified training. Scand. J. Med. Sci. Sports 2017, 27, 925-934. [CrossRef] [PubMed]

27. Reed, J.L.; De Souza, M.J.; Kindler, J.M.; Williams, N.I. Nutritional practices associated with low energy availability in Division I female soccer players. J. Sports Sci. 2014, 32, 1499-1509. [CrossRef]

28. Vanheest, J.L.; Rodgers, C.D.; Mahoney, C.E.; De Souza, M.J. Ovarian suppression impairs sport performance in junior elite female swimmers. Med. Sci. Sports Exerc. 2014, 46, 156-166. [CrossRef] [PubMed]

29. Bingham, S.A.; Gill, C.; Welch, A.; Day, K.; Cassidy, A.; Khaw, K.T.; Sneyd, M.J.; Key, T.J.A.; Roe, L.; Day, N.E. Comparison of dietary assessment methods in nutritional epidemiology: Weighed records v. $24 \mathrm{~h}$ recalls, food-frequency questionnaires and estimated-diet records. Br. J. Nutr. 1994, 72, 619-643. [CrossRef]

30. Fahrenholtz, I.L.; Sjödin, A.; Benardot, D.; Tornberg, Å.B.; Skouby, S.; Faber, J.; Sundgot-Borgen, J.K.; Melin, A.K. Withinday energy deficiency and reproductive function in female endurance athletes. Scand. J. Med. Sci. Sports 2018, 28, 1139-1146. [CrossRef]

31. Woods, A.L.; Garvican-Lewis, L.A.; Lundy, B.; Rice, A.J.; Thompson, K.G. New approaches to determine fatigue in elite athletes during intensified training: Resting metabolic rate and pacing profile. PLoS ONE 2017, 12, e0173807. [CrossRef]

32. Woods, A.L.; Rice, A.J.; Garvican-Lewis, L.A.; Wallett, A.M.; Lundy, B.; Rogers, M.A.; Welvaert, M.; Halson, S.; McKune, A.; Thompson, K.G. The effects of intensified training on resting metabolic rate (RMR), body composition and performance in trained cyclists. PLoS ONE 2018, 13, e0191644. [CrossRef]

33. Hooper, D.R.; Kraemer, W.J.; Saenz, C.; Schill, K.E.; Focht, B.C.; Volek, J.S.; Maresh, C.M. The presence of symptoms of testosterone deficiency in the exercise-hypogonadal male condition and the role of nutrition. Eur. J. Appl. Physiol. 2017, 117, 1349-1357. [CrossRef]

34. Geesmann, B.; Gibbs, J.C.; Mester, J.; Koehler, K. Association Between Energy Balance and Metabolic Hormone Suppression During Ultra-Endurance Exercise. Int. J. Sports Physiol. Perform. 2017, 12, 984-989. [CrossRef] 